\title{
Bioética de la muerte de Sigmund Freud. ¿Eutanasia o apropiación?
}

\author{
GUSTAVO FIGUEROA
}

\section{Bioethics of Sigmund Freud's death. Euthanasia or appropriation?}

The death of Freud raises the ethical dilemma about euthanasia. It can be characterized as indirect active euthanasia according to the rule of double effect, or terminal sedation, or palliated death. The primacy of the principle of autonomy over non-maleficence, conditioned the physician's attitude toward his patient Freud. The physician-assisted death was and remains punishable in western medicine. Therefore, a fundamental tradition was infringed. In contrast, the present study attempts to characterize the final position of Freud himself to his death and called it appropriation of his finitude; he assumes his being-unto-death, that is, he now projects his being not as a being-at-his-end but as a being-unto-end, indicating thereby that he understood that the end always penetrated his whole existence.

(Rev Med Chile 2011; 139: 529-534).

Key words: Biography; Conscious sedation; Ethics; Euthanasia.
Departamento de

Psiquiatría, Escuela de Medicina, Universidad de Valparaíso.

Recibido el 1 de septiembre de 2010, aceptado el 10 de marzo de 2011.

Correspondencia a Dr. Gustavo Figueroa Fono: (32) 2693671 (32) 2508550 E-mail: gfigueroacave@ gmail.com
L a enfermedad final de Sigmund Freud (18561939) planteó problemas morales que, por ocurrir antes del nacimiento de la bioética, se resolvieron desde perspectivas tradicionales en medicina. Sin embargo, la riqueza y profundidad del material nos permitió analizar que, detrás de la revelación de su diagnóstico, existía una novedad ética que superaba ampliamente la concepción consagrada, que denominamos veracidad ${ }^{1-3}$. El presente estudio investiga su muerte porque postula que puede contribuir a alcanzar una visión conceptual y clínicamente diferente de la actual, esta vez sobre los dilemas éticos del morir.

\section{Incertidumbres clínicas}

El 23 de septiembre de 1939 murió después que su médico le aplicara morfina. Su enfermedad surgió hacia 1923 cuando al examinar su paladar sospechan un cáncer. El 7 de abril se confirma como "leucoplasia proliferativa papilar" y es sometido a una extirpación amplia del maxilar superior e irradiación. Desde esos instantes hasta su muerte es operado en 33 ocasiones, es expuesto a repetidas radioterapias, tolera prótesis absolutamente mortificantes que separan la boca de la cavidad nasal, su dolor crece sostenidamente hasta hacerse casi insoportable, sufre de otitis a repetición, come a solas por impedimentos para masticar, habla y escucha dificultosamente ${ }^{4-6}$. Empero su productividad intelectual continuó de manera ininterrumpida: elabora nuevas hipótesis, publica libros revolucionarios, psicoanaliza diariamente a ocho pacientes, dirige la Sociedad Psicoanalítica. En junio de 1938 escapa precipitadamente de Austria con sus familiares por el inminente peligro nazi y se instala en Londres donde mantiene todas sus actividades hasta el final.

Freud comprometió a su médico personal, Felix Deutsch, a que le revelara toda la verdad y "lo ayudara a abandonar este mundo en actitud digna (mit Anstand)". Deutsch temió tan intensamente la posibilidad del suicidio que optó por ocultarle el diagnóstico de cáncer. Freud se indignó con lo que denominó "traición" ("¿Con qué derecho?", Mit welchem Recht?) y, tras dar por terminada su relación profesional, desde 1928 hasta su muerte 
escogió a Max Schur como su médico después de solicitarle que le comunicara siempre toda la verdad. Y concluyó: "prométame algo más: que cuando llegue el momento no me hará sufrir innecesariamente (unnötig quälen lassen)" 7,8 .

A partir de junio de 1939 su condición empeora velozmente. Su cáncer se ulcera en la mejilla y despide mal olor, los tormentos físicos se hacen casi intolerables, obstrucción progresiva para tragar, se ve forzado a reposar largamente aunque se mantiene activo intelectualmente terminando sus libros y atendiendo a duras penas sus pacientes. En agosto cierra definitivamente su consulta, escribe su postrera frase en su Chronik, "Pánico de guerra", la fetidez hace que su perro huya de su lado, sus amigos se despiden. Su cansancio aumenta en septiembre, las noches son insufribles, se muestra agradecido hacia sus seres queridos, casi no consigue deglutir, estado caquéctico, no se queja ni irrita y, tal como lo determinó al inicio de su mal, no admite que le prescriban sedantes porque "prefiero pensar en medio del tormento a no estar en condiciones de pensar con claridad"9-12.

Los informes desde el 21 de septiembre son contradictorios. Existen tres versiones de Schur - dos de las cuales no publicó después de asesorarse con abogados-, la recopilación final de Jones ${ }^{13}$, entrevista a Helen Schur, cartas inéditas de Anna Freud y su sobrino Harry, y material confidencial clasificado ${ }^{14}$. Freud llama a Schur y le dice "usted recuerda nuestra primera conversación en que prometió no dejarme en la estacada cuando llegara el momento. Ahora no es sino tormento y no tiene sentido". Al reasegurarlo Schur, Freud agregó "Ich danke Ihnen, se lo agradezco". Aquí comienzan las diferencias sutiles. Según Jones, "prometió darle una sedación adecuada" y al día siguiente le inyectó $20 \mathrm{mg}$ de morfina. Por su parte, Schur escribió que le dio una segunda inyección "después de doce horas". Pero en carta privada a Anna Freud le dice que alteró la versión oficial sobre dosis y número de inyecciones: treinta miligramos en vez de veinte y tres inyecciones en lugar de dos. Schur anota que Freud le dijo después "Sagen Sie es der Anna", "dígale a Anna sobre esto". Pero su reporte no publicado expresa "Besprechen Sie es mit der Anna", que significa "discútalo" o "háblelo" con Anna, que está en consonancia con lo que agregó seguidamente: "y si ella piensa que está bien, entonces póngale fin a esto". Siempre según el inédito, Anna luchó contra la idea pero al final se resignó tristemente con la decisión de poner término a la agonía de su padre. Gay califica de "suicidio estoico" el de Freud, ejecutado en su nombre ya que él estaba demasiado débil para llevarlo a cabo personalmente, mientras que Schur temió que legalmente se considerara eutanasia y que Anna cargara con sentimientos de culpa.

\section{La equívoca eutanasia}

Al igual que la humanidad entera, la medicina tiene una larguísima tradición de controversias en torno a la eutanasia, que se han reavivado por las revolucionarias tecnologías, originando posturas bioéticas irreconciliables o apenas compatibles. Las características decisivas son las siguientes: 1) Acto ejecutado activamente por el médico; 2) sobre el paciente; 3) con intención directa y expresa de poner fin a la vida y 4) a petición explícita e indudable de éste. En el caso de Freud, éste debería haber tenido el propósito inequívoco de terminar con su vida y la muerte resultó un efecto deseado - no simplemente tolerado- y ejecutado por Schur.

La complejidad clínica justifica plantearse contrariamente si el concepto más adecuado sería "sedación terminal". El propósito de Schur era calmar sus intensísimos sufrimientos corporales y psíquicos aunque poseía la certeza casi absoluta de que, al hacerle perder la conciencia, le sobrevendría su muerte. Correspondería a lo que en otra terminología se denomina mercy killing, poner término a su vida aunque por compasión. Por decirlo así, si hubiera dispuesto de otro medio para calmarlo Schur lo habría empleado, como lo hizo repetidamente hasta entonces, pero no existía y por esto no cabía sino sacrificar su vida por piedad.

Una variedad del argumento anterior recuerda que eran las condiciones físicas extremas de Freud las que hacían no viable su existencia posterior al empleo de morfina, no la finalidad del médico. Como el uso de analgésicos estaba plenamente justificado por ser la única terapia efectiva, la responsable de la muerte fue la causa somática preexistente; el cuerpo, por su fragilidad extrema, no toleraba la dosis adecuada, y no fue la intención de Schur exceder la cantidad.

El recurrir a este procedimiento de muerteinducida-por-el-médico se denomina eutanasiaactiva-indirecta. Aunque transgrede las leyes vigentes en la casi totalidad de los países aún hasta 
hoy, los requisitos fundamentales que se tendrían que haber cumplido en Freud son: 1) petición voluntaria siendo una persona competente; 2) relación médico-enfermo prolongada; 3 ) toma de decisión conjunta e informada; 4) ambiente favorable, aunque crítico, para la toma de la decisión; 5) rechazo reflexionado de otras alternativas; 6) manifestación de deseo de morir expresado durante un tiempo prolongado; 7) sufrimiento insoportable o enfermedad intratable final; y 8) utilización de un método lo menos doloroso y más cómodo posible. Si Freud hubiera recurrido a este procedimiento lo habría ejecutado siguiendo el principio del doble efecto, regla que se remonta a Platón y Tomás de Aquino. Una acción que provoca consecuencias buenas y malas puede ser éticamente aceptable cuando existe una proporcionalidad entre estas consecuencias y lo directamente querido: son los resultados beneficiosos lo pretendido, no sus secuelas indeseables, las cuales son puramente toleradas. Para ello se tendría que estar seguro que Freud no solicitaba primariamente la muerte por intermedio de Schur.

Un tercer enfoque postularía una muerte paliada (palliated death). El morir de Freud formó parte del debido cuidado médico (due care), que siempre tiene que ser integral, continuado y de calidad. El énfasis se pone en que el deber profesional primario de Schur fue entregar la mejor calidad de vida posible hasta el final ${ }^{15-22}$.

Sin embargo, el caso es más complejo. Freud se encontraba: 1) En una situación de muerte inminente; 2) la muerte la había enfrentado hasta límites casi sobrehumanos sin poner jamás en riego su vida (biológica e intelectual); 3 ) nunca rechazó reflexivamente otras alternativas, sometiéndose responsablemente a todas ellas durante 16 años; 4) quería terminar con el "tormento" (Quälerei); y 5) necesitaba poner fin a su falta de sentido. Cabe la pregunta: lo que Freud buscaba ¿era la muerte misma o resolver el tormento y especialmente la falta de sentido (Sinn) de su vida?

\section{Autonomía}

La bioética americana ha acentuado con firmeza la primacía de la autonomía del paciente en la toma de decisiones médicas a pesar de reconocer que es un principio prima facie, esto es, debe ser aplicado excepto que las condiciones o conse- cuencias prioricen otro principio alternativo ${ }^{22}$. Se ha calificado al caso de Freud como un ejemplo paradigmático de autonomía, representante de un principio que él nos enseñó a respetar antes que fuera objeto de defensas apasionadas en la década del 70, y que se ha convertido en una conquista irrenunciable de la medicina, porque supera definitivamente el lastre del paternalismo histórico ${ }^{23}$.

Tres consideraciones de Cortina recuerdan empero que la autonomía es más complicada que la utilizada en bioética ${ }^{24}$. Primero, la autonomía del Informe Belmont no coincide con la de Kant, de donde aparentemente procedería. Para el Informe se trata de "actos" o elecciones individuales acerca de su propio bien, que cumplen con los requisitos de intencionalidad propia, conocimiento cabal y ausencia de control externo, como en el consentimiento informado ${ }^{25}$. Inversamente Kant habla de la "persona" y la "buena voluntad", por tanto, de la capacidad de universalización, porque para éste la dignidad humana consiste en darse leyes a sí mismo y éstas son producto de una voluntad legisladora que se guía siguiendo el punto de vista de la validez universal de la ley y no del voluntarismo caprichoso. Frente a las "acciones autónomas" «individualizadoras» se contrapone la "persona autónoma" "universalizadora», lo que explica que en los escritos kantianos nunca se apela a la autonomía en relación a los enfermos ${ }^{26}$.

Segundo, filósofos actuales decisivos (Nietzsche, Heidegger, Ricoeur, Foucault) rechazaron como engañoso el concepto de "sujeto autónomo" porque sus dos rasgos definitorios, autotransparencia completa y autodeterminación incondicional, son ilusiones del racionalismo moderno. Postular una autoconciencia absoluta y una volición sin condicionamientos le lleva a creerse autosuficiente, esto es, al pretenderse conocedor y ejecutor desde su interioridad ilimitada le legitima para sentirse soberano y señor sobre su cuerpo, presupuestos del idealismo cartesiano ya no sostenibles.

Tercero, se produce un malentendido si no se diferencia entre "autonomía" y "autorrealización" del enfermo: la autonomía adopta el punto de vista de "lo universal" y la autorrealización de "lo individual". Autonomía: la voluntad lo es cuando se orienta por aquello que todos podrían querer; la razón, cuando se justifica con argumentos que siguen un juicio imparcial; el sujeto, cuando parte de la subjetividad-intersubjetividad, de modo que 
se califica una decisión como moralmente correcta cuando afecta a los seres humanos en conjunto y así todos son considerados potenciales interlocutores válidos. Se trasciende el "yo pienso" por el "nosotros argumentamos", el "interés individual" por los "intereses universalizables", el "yo determino" por el "interlocutor válido"27-29.

Contrariamente la autorrealización señala lo individual entendido como lo propio, lo perteneciente al mundo espiritual del sujeto, a sus deseos, esperanzas, ambiciones, propósitos que encuentran su valoración al interior de una biografía única e irrepetible. Por ello, frente a los razonamientos acerca de la corrección de las normas, se alza el sentido dentro de una historia asumida con responsabilidad. Ante las mejores "razones" están los "significados" más plenos, lo "universalizable" enfrentado a lo "intransferible", la comprensión de "lo humano" frente a la comprensión de "lo biográfico", "lo correcto" de la norma a "lo bueno" de las elecciones.

Caracterizamos la "autonomía" como una "ética-de-mínimos", los deberes esenciales que son exigibles que cumpla toda persona si sus acciones pretenden ser verdaderamente humanas. Inversamente, la "aurorrealización" significa "ética-de- máximos" - "ética-de-la-convicción" (Gesinnungsethik), según Weber-, los ideales morales superiores o excelencias a los que se tiene que aspirar, pero que no se pueden imponer coactivamente ni ordenar que los cumpla todo ser humano ${ }^{30,31}$.

En el caso de Freud, Schur siguió tanto una "ética-de-mínimos" como una "ética-de-máximos". Esto significó que osciló permanentemente en considerar a Freud "interlocutor válido" así como individuo único poseedor de ideas propias con respecto al morir; le señaló el alcance ético de las normas involucradas pero dialogó sobre los argumentos personales aducidos por él; respetó sus obligaciones de médico aunque atendió sus necesidades clínicas urgentes; se comprometió con el principio de no-abandono empero fomentó que Freud eligiera las circunstancias concretísimas de su tratamiento final.

Pero lo que estaba en juego primariamente era el principio de no-maleficencia, lo que significa prioridad ética frente al de automía. Como se mencionó, el médico que mata ejerciendo su profesión es condenado en todas las sociedades occidentales.

\section{Propiedad}

Tres muertes fueron determinantes en su vida. A los 2 años, su hermano menor Julius, de quien jamás habló. En 1896, su padre, "la pérdida más decisiva en la vida de un hombre"32. En 1920, su hija preferida Sophie, "muy en lo profundo, el sentimiento de una herida narcisista del que jamás me liberaré". El saber de su cáncer lo precipitó en una experiencia absolutamente inédita: su muerte como hecho absoluto. Freud podía suicidarse, negarla, rebelarse o asumirla y él escogerá esta última, que supone una opción ética específica.

Esta experiencia única desazonante (unheimlich) le reveló y des-cubrió dos ámbitos fundamentales: su facticidad y su finitud. Facticidad quiere decir que sus posibilidades no siempre las puso él, que estaba-ya-arrojado (schon-sein) entre posibilidades y realidades que él ni las había producido ni controlaba por completo y, a pesar de ello, tenía-que-hacerse-cargo de éstas, pero ahora desde su posibilidad última de ser-mortal. Tarea paradojal, puesto que tiene-que ( $z u$-sein) elegir esta elección, su muerte, que en sí es impuesta, inevitable e intransferible. Tarea a contrapelo, porque es invertir su referencia a sí, desde sentirse dueño de sus acciones a saberse constreñido; esto es, desde "autodeterminarse" a "autoelegirse" ¿cómo así? La autodeterminación (Selbstbestimmung) de su existir consistía en disponer de sí-mismo a voluntad, imponer sus condiciones, controlar las circunstancias, exigir que se hicieran realidad sus proyectos y ordenar que otros los cumplieran. Lentamente comienza a visualizar que esto que había constituido uno de sus atributos centrales empieza a mostrar sus insuficiencias, eran autoilusiones antes que realidad. La exigencia impuesta a Deutsch de que se le diga la verdad continúa con Schur, pero con distinto matiz. Ahora entiende que saber o no saber la verdad de su vida, esto es, que tenga o desconozca su sentido, es una elección suya, no una exigencia que él imponga o a él se le obligue. Vale decir, pasa de una soberanía incondicionada o "autodeterminación" a una "autoelección” (Selbstwahl): aceptación de sí que acata sus límites, carencias y penurias; aún más, sin ser sus insuficiencias generadas o creadas por él, precisa elegirlas, adueñárselas e incorporalas en su ser ${ }^{33-36}$.

Por otra lado, su finitud: Heidegger ha denominado el asumirla de manera radical resolución anticipadora (vorlaufende Entschlossenheit), esto 
es, un giro y transformación de su comprensión cotidiana de sí-mismo que lo impele, por vez primera, a experimentarse en su verdad última, que su vida es finita y ser-para-la-muerte. Es un novedosísimo saber de sí-mismo y que consiste en anticiparse con lucidez inédita a la posibilidad de la imposibilidad. ¿Qué quiere decir? Como ser humano, Freud antes que "tener" posibilidades "es" sus posibilidades, o sea, sus posibilidades son su modo de ser: posibilidad de ser padre, psicoanalista, terapeuta. Cada una de sus acciones concretas era ejecutada en-vistas-de estas posibilidades, podía ganarlas o malograrlas. Ahora se enfrenta con su posibilidad "más propia, intransferible e insuperable", su muerte en tanto posibilidad real y no simple dato. Esto impone reinterpretarse oponiéndose con violencia a su autocomprensión habitual, no en cuanto al contenido de sus posibilidades (dedicarse a esto o lo otro), ni según el cálculo que considera sus conveniencias (más o menos provecho); es comprenderse radicalmente: desde-su-ser-para-el-final (Sein-zum-Ende), desde esta posibilidad extrema de ser-ya-nunca-más el ser que puede ser.

La última conversación con Schur comprueba que no solamente enfrenta, sino que "elige" y "hace-propio" su morir, porque para el hombre la muerte, al igual que el vivir, puede ser-impropia o hacerse-propia (sich-zueigen-sein). Habitual y regularmente estamos sumidos en la im-propiedad tranquilizadora o inautenticidad autoevasiva, en el mundo del "uno" (das Man), o de "la gente": se piensa lo que "se"piensa, "se" muere como "la gente" muere. Cuando Freud le recuerda a Schur que no lo deje en la estacada y hable con su hija, y afirma que su vida carece-de-sentido, se distancia tanto del morir como "toda-la-gente" como del voluntarista "soy-yo-el-único-quedetermina-mi-muerte". Lo que afirma es que su vida es autointerpretación y por ello le es inherente poseer diferentes sentidos. La apropiación (Eigentlichkeit) es el sentido auténtico, el que Freud asume en el momento en que desenmascara el sentido-cotidiano-y-habitual-y-aquietador, el de "la-gente". Ahora comprende que es su final el que da el sentido último. En lugar de estar-al-final ( $Z u$-Ende-sein) es un ser-para-el-final (Sein-zumEnde), es el final es el que infunde de sentido a su existencia y la convierte en propiamente suya. Cuando habla de pérdida-de-sentido significa rechazo del sentido-cotidiano-y-habitual pero asunción del sentido auténtico, un poder-ser-símismo-en-cuanto-posibilidad. Esto es, su morir se transfigura de "hecho-constatable" en lo que realmente es, posibilidad pura -posibilidad de la imposibilidad ${ }^{37-40}$. Por ello acata y se sume en el silencio: no emite palabras ni pronuncia discursos, porque no es un "hecho" o un "algo" de que hablar o parlotear sino la "nada".

\section{Contraposiciones}

La bioética ha planteado las diversas modalidades de eutanasia desde la muerte entendida como realidad objetiva. La autonomía y no-maleficencia constituyen principios que determinan diferentes elecciones morales siguiendo este presupuesto: eutanasia directa, indirecta y muerte paliada.

Freud entendió la muerte como posibilidad. Su morir es pérdida-de-sentido- cotidiano pero revelación en tanto "pura posibilidad" o "nada" de ser: la-posibilidad-de-la-imposibilidad. Si su vida consistió en "ser" sus posibilidades, su morir fue asumir esta "nada" o posibilidad como auténtica al momento de apropiársela e hizo de su ser-finito un silencioso ser-para-el-fin.

\section{Referencias}

1. Figueroa G. Ética de la revelación del diagnóstico. El caso de Freud. Rev Chil Neuro-Psiquiat 1997; 35: 147-60.

2. Figueroa G. La revelación del diagnóstico: el lugar de la beneficencia, autonomía y veracidad en la ética médica. Rev Med Chile 1998; 126: 569-76.

3. Figueroa G. Al saber la verdad Edipo se arrancó los ojos. Bioética de la revelación del diagnóstico. Rev Chil Neuro-Psiquiat 2005; 43: 148-58.

4. Schur M. Freud. Leben und Sterben. Frankfurt: Fischer, 1972.

5. Romm S. The unwelcome intruder. Freud's struggle with cancer. New York: Praeger, 1983.

6. Kollbrunner J. Der Kranke Freud. Stuttgart: Klett-Cotta, 2001.

7. Deutsch F. Reflections on Freud's one hundred birthday. Psicosom Medicine 1956; 18: 279-83.

8. Jucovy ME. May 19, 1964. The problem of death in Freud's writings and life (Fourteenth Freud Anniversary Lecture). Max Schur, MD. Psychoanal Quart 1965; XXXIV: 144-7.

9. Freud S. Abriß der Psychoanalyse. Gesammelte Werke XVII. Frankfurt: Fischer, 1940. p. 63-138. 
10. Freud S. Some elementary lessons in Psycho-Analysis. Gesammelte Werke XVII. Frankfurt: Fischer, 1940. p. 141-7.

11. Freud S. Tagebuch 1929-1939. Kürzeste Chronik. Frankfurt: Stroemfeld, 1996.

12. Zweig S. Briefwechsel mit Sigmund Freud, Rainer Maria Rilke und Arthur Schnitzler. Frankfurt: Fischer, 1987.

13. Jones E. Das Leben und Werk von Sigmund Freud. 3 Bände. München: DTV, 1984.

14. Gay P. Freud. A life for our time. New York: Norton, 1988.

15. Gracia D. Como arqueros al blanco. Estudios de bioética. Madrid: Triacastela, 2004.

16. Enck RE. Drug-induced terminal sedation for symptom control. Am J Hosp Paliat Care 1991; 8: 3-5.

17. Quill TE. Caring for patients at the end of life. New York: Oxford University Press, 2001.

18. Beauchamp TL, Childress JF. Principles of biomedical ethics. $5^{\text {th }}$ edition. New York: Oxford University Press, 2001.

19. Kaam FM. Physician-assisted suicide, the doctrine of double-effect, and the ground of value. Ethics 1999; 109: 586-605

20. Cavanaugh TA. Double-effect reasoning: doing good and avoiding evil. Oxford: Clarendon Press, 2006.

21. Figueroa G. Responsabilidad profesional: máximos, mínimos, excelencia y veracidad. Rev Med Chile 2006; 134: 233-9.

22. Saunders C, Baines M, Dunlop R. Living with dying: $A$ guide to palliative care. Oxford: Oxford University Press, 1995.

23. McCue JD, Cohen LM. Freud's physician-assisted death. Arch Intern Med 1999; 159: 1521-5.

24. Cortina A. Ética del discurso y bioética. En: Blanco D, Pérez JA, Sáez L, editores. Discurso y realidad. En debate con K-O Apel. Madrid: Trotta, 1994. p. 75-89.

25. Faden RF, Beauchamp TL. A history and theory of infor- med consent. New York: Oxford University Press, 1986.

26. Kant I. Kritik der praktischen Vernunft. Band 6. Darmstadt: Wissenschaftliche Buchgesellschaft, 1968. p. 107300.

27. Ricoeur P. Soi-même comme un autre. Paris: Seuil,1990.

28. Rodríguez R. Del sujeto y la verdad. Madrid: Síntesis 2004.

29. Apel K-O. Transformation der Philosophie. 2. Bände. Frankfurt: Suhrkamp, 1973

30. Cortina A. Ética mínima. Introducción a la filosofía práctica. 3a edición. Madrid: Tecnos, 1992.

31. Weber M. Politik als Beruf, Wissenschaft als Beruf. Berlin: Dunker \& Humboldt, 1959.

32. Anzieu D. Freuds Selbstanalyse und die Entdeckung der Psychoanalyse. 2 Bände. München : Verlag Internationale Psychoanalyse, 1990.

33. Heidegger M. Sein und Zeit. 10. Auflage. Tübingen: Niemeyer, 1963.

34. Heidegger M. Die Grundprobleme der Phänomenologie. Gesamtausgabe 24. Frankfurt: Vittorio Klostermann, 1997.

35. Heidegger M. Was ist Metaphysik? 7. Auflage. Frankfurt: Vittorio Klostermann, 2007.

36. Rivera JE. Jemeinigkeit. En: Rivera JE. Heidegger y Zubiri. Santiago de Chile: Editorial Universitaria/Ediciones Universidad Católica de Chile, 2000. p. 33-47.

37. Ortega y Gasset J. El hombre y la gente. Obras Completas. VII. Madrid: Revista de Occidente, 1948. p. 69-273.

38. Heidegger M. Brief über den "Humanismus". Gesamtausgabe 9. Frankfurt: Vittorio Klostermann, 1976. p. 313-64.

39. Heidegger M. Zollikoner Seminare. Protokolle-Zwiegespräche-Briefe. 2. Auflage. Frankurt: Vittorio Klostermann, 1994.

40. Heidegger M. Ontologie. (Hermeneutik der Faktizität). Gesamtausgabe 63. Frankfurt: Vittorio Klostermann, 1982. 